\title{
Fracture of the Subcutaneous Patch Electrode in a Patient With an Implanted Cardioverter-Defibrillator
}

\author{
Goran Milasinovic, PhD; Vera Jelic, PhD; Dragutin Savic, PhD; \\ Sinisa U. Pavlovic, PhD; Milos Velinovic, $\mathrm{PhD}$
}

\begin{abstract}
There are more than 20 years of experience with implantation of defibrillator devices in humans and the procedure is an important therapeutic option for patients at high risk of life-threatening ventricular arrhythmias. The incidence of new defibrillator implantation has gradually increased, being used even in children, although pediatric use is associated with several complications, especially with epicardial systems, including fracture of the subcutaneous patch $3-5$ mainly because of growth? We present a case of subcutaneous patch electrode fracture in the left axillary pectoral region of a patient who needed the patch for effective defibrillation, and we discuss the methods of treatment. (Circ J 2005; 69: 116-118)
\end{abstract}

Key Words: Cardioverter-defibrillators; Patch electrode; Tetralogy of Fallot

A

23 year-old female born in 1978 with tetralogy of Fallot underwent palliative surgery when she was 1 year old and the cardiac abnormality was completely corrected when she was 3 years of age. At the age of 12 , ventricular tachycardia (VT) appeared (2 forms with rates of 190 and 150 beats/min, respectively). Surgical ablation of the ventricular foci was unsuccessful and because of recurrent VT (same form and rate), an implantable cardioverter-defibrillator (ICD) was implanted in 1992 in St Bartholomew's Hospital, London. A Medtronic 6963 electrode was positioned in the superior vena cava (SVC)/right atrium (RA) junction and a Medtronic 6966 electrode was placed in the right ventricular apex $(\mathrm{R}$ wave $7.8 \mathrm{~V}$, threshold $0.7 \mathrm{~V}$ at $0.5 \mathrm{~ms}$, impedance $308 \mathrm{ohms}$ ). Because of unreliable termination of ventricular fibrillation (VF), it was decided to insert another Medtronic 6963 electrode in the coronary sinus. Five days after implantation, the coronary sinus lead had moved and defibrillation was unsuccessful. A Medtronic 6999-50 subcutaneous patch electrode was then placed in the left axillary position, and defibrillation was effective. Because of depletion, the ICD battery was changed in the Pacemaker Center, Institute for Cardiovascular Diseases, CSS, Belgrade, Yugoslavia (Medtronic, Jewel 7219B) in 1996. In the regular 3 month follow-ups the patient was controlled with telemetry and the implanted ICD functioned normally until December 2000. In the 54 months of follow-up there were 37 episodes of VT/VF (86\% were treated with antitachycardia pacing (ATP), $12 \%$ with cardioversion (CD) and $2 \%$ with defibrillation (DC)) and 2,314 episodes of NSVT.

In March 2001, before replacement of the new unit (GEM III VR $7231 \mathrm{Cx}$ ), fracture of the subcutaneous patch electrode was detected by X-ray (Figs 1,2), despite there

(Received June 19, 2003; revised manuscript received November 20, 2003; accepted November 26, 2003)

Pacemaker Center, Institute of Cardiovascular Diseases, Clinical Center of Serbia, Belgrade, Serbia and Montenegro

Mailing address: Goran Milasinovic, MD, PhD, FESC, Pacemaker Center, Institute for Cardiovascular Disease, Clinical Center of Serbia, K. Todorovica 8, 11000 Belgrade, Serbia and Montenegro. E-mail: goran_milas@yahoo.com being no history of a fall or stroke, and no growth in height and weight during the last 7.5 years. The last ICD defibrillation therapy for fast VT of 190 beats/min had registered 9 months before the patch fracture was detected. The patient underwent implantation of a new subcutaneous coil electrode (Medtronic SQ 6996) with an intraoperative defibrillation threshold of $12.5 \mathrm{~J}$. The fractured subcutaneous patch electrode was isolated (Fig 3).

Replacement of the ICD device in the abdominal position with a subcutaneous SQ electrode was successful. There were no operative or perioperative complications. The operating time was $105 \mathrm{~min}$ and that of fluoroscopy was $8 \mathrm{~min}$. The sensing was $12 \mathrm{mV}$ and pacing threshold $1 \mathrm{~V} / 0.5 \mathrm{~ms}$. The defibrillation threshold was $12 \mathrm{~J}$ at the time of ICD replacement and the high-voltage impedance was $32 \mathrm{ohms}$. The ICD was programmed as a two-zone device, with a VT zone (400-320 ms: ATP, cardioversion and defibrillation therapy) and VF zone $(<320 \mathrm{~ms}$ : defibrillation therapy only) and VVIR pacing rate of 60-120 beats/min. During the first 3 months of follow-up after the replacement, the defibrillation threshold was not retested because of a recorded fast VT (190 beats/min) and successful termination with the first $20 \mathrm{~J}$ DC shock. In addition, 5 episodes of VT ( 150 beats/min) were successfully terminated with burst ATP. Neither inappropriate ICD therapy nor leadrelated complications was recorded.

\section{Discussion}

ICD implantation in children is infrequent because of the low incidence of sudden cardiac death, estimated at 1-8 deaths per 100,000 patients per year, 6 and is made mainly in patients with either congenital or primary electrical heart diseases. The use of endocardial lead systems in children is less common than epicardial lead systems; these may be the cause of an increased risk for restrictive cardiac dysfunction and for patients undergoing more than one thoracotomy?

Fischbach et al first reported a new nonthoracotomy lead configuration using a single-coil transvenous electrode with an abdominally placed 'active can' ICD device that 


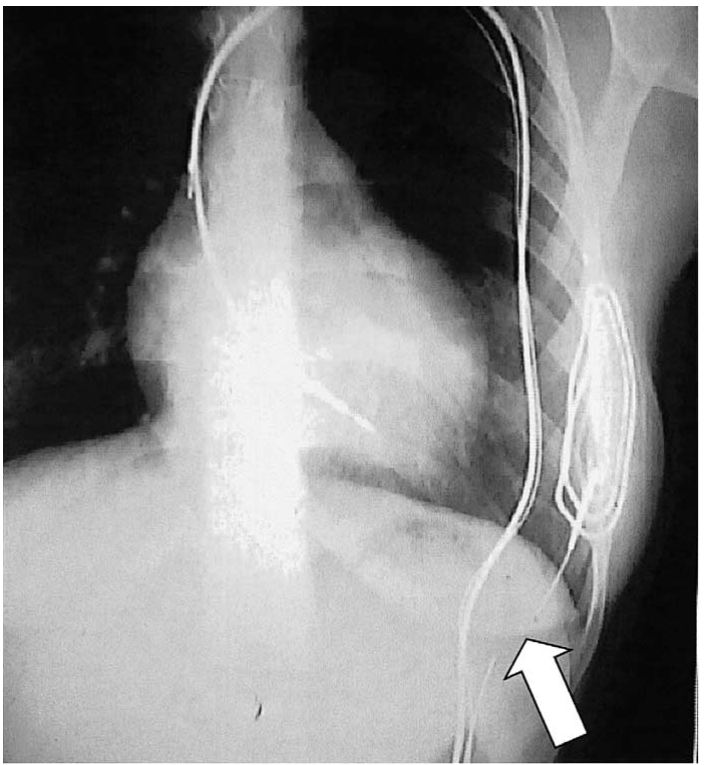

Fig 1. Chest X-ray in the postero-anterior view showing the fractured subcutaneous patch electrode.

makes ICD placement possible even in smaller children with a body weight below $40 \mathrm{~kg}$ (they reported 5 children, age $8-16$ years, weight $21-50 \mathrm{~kg}$, mean 35$)$ ?

The use of an epicardial or nontransvenous system in a growing, active child is of concern because the fragility of the lead and patch system may, when broken, result in inappropriate shocks because of oversensing (leads) or suboptimal delivery of energy (broken patch), ${ }^{1,8-11}$

Gradaus et al recently reported successful use of a subcutaneous array lead in 2 children with complex congenital heart diseases that were cured with abdominally placed nontransvenous ICDs?

We have shown that the new subcutaneous coil electrode can be used to replace a fractured subcutaneous patch electrode, needed for clean arrhythmia termination with excellent defibrillation thresholds and successful defibrillation results. This could be the way of treating patients with an abdominally placed ICD who need a subcutaneous electrode for safe defibrillation.

To the best of our knowledge there are no other reports of lead fracture of the Medtronic 6999-50 subcutaneous patch electrode system in children as a long-term complication. Fracture of the same subcutaneous patch electrode has been documented in 2 elderly patients $(2.5 \%)$, but in contrast to the present patient, it was a short-term complication (within the first month after the implantation). There are reports of the failure of the Medtronic epicardial patches, models 6987/6921, which are composed of the same material as Medtronic subcutaneous patches model 6999 (multifilar MP35N alloy as a conductor, platinum alloy mesh material with silicone rubber insulation). In those cases, only fluid penetration within the lead insulation and crinkling of the patch were noticed, without any obvious lead fracture!2 Of the Medtronic ICD leads, the Transvene model 6936/6966, a coaxial polyurethane ICD lead, invented in the search for better handling characteristics, could be prone to structural failure (oversensing and inappropriate shocks are the most common signs of failure). The manufacturer's reports indicate that high-voltage coil fracture and $80 \mathrm{~A}$ polyurethane (Pellethane $80 \mathrm{~A}$ ) defects are

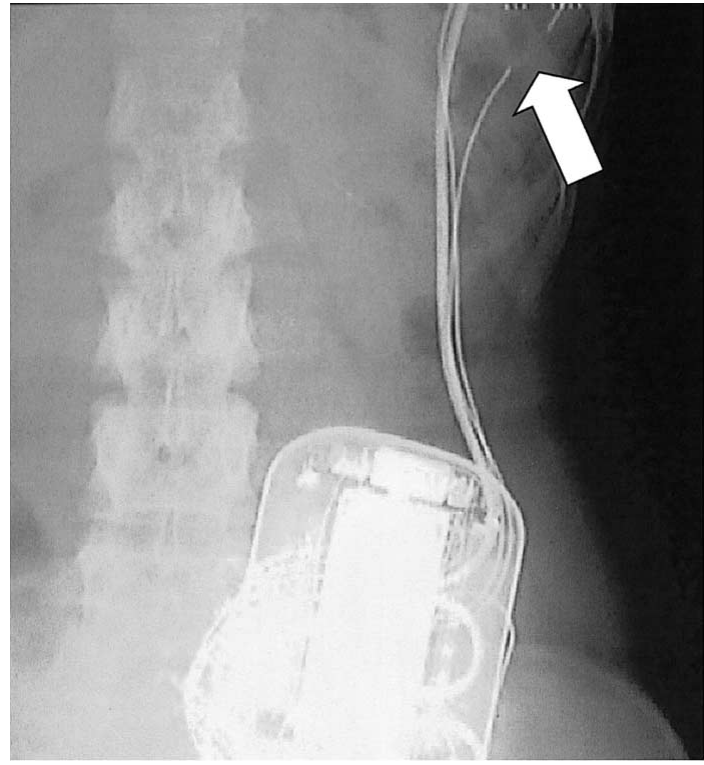

Fig 2. Abdominal X-ray in the postero-anterior view showing the fractured subcutaneous patch electrode.

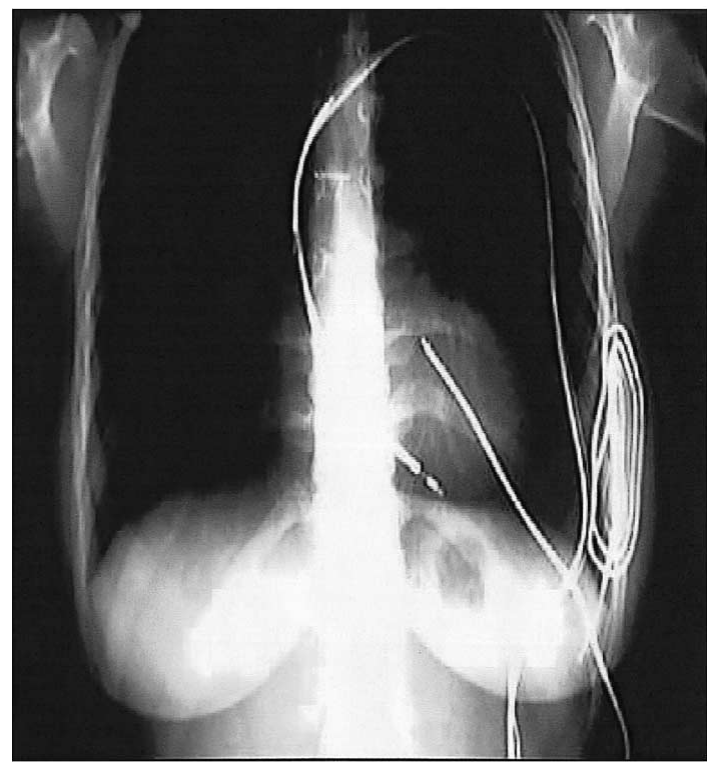

Fig 3. Chest X-ray in the postero-anterior view showing the subcutaneous coil SQ electrode in place.

the predominant causes of lead failure! ${ }^{13,14}$ The insulation material in the Medtronic subcutaneous patch electrode model 6999-50 is silicone rubber instead of polyurethane and silicone has total reliability for more than 30 years ${ }^{15}$

The site of the lead fracture in the present patient was around the diaphragm (lower edge of the ribs), which was also the site described by Frame et al in 2 elderly patients! ${ }^{16}$ In contrast, Korte et al described the point of subcutaneous patch fracture as the junction of the patch and the body of the lead (lead material: multifilar MP35N alloy as a conductor, platinum coil electrode with silicone rubber insulation) and in another case the fracture was $1 \mathrm{~cm}$ distal to the patch? In both of those elderly patients the fracture point was proximal to the costal margin and no mechanical forces were observed before the fracture was detected. 
The definite cause of the lead fracture in the present patient is unknown. Although she had finished growing for at least 7.5 years, we consider that body growth played an important role, because the patient underwent the initial implantation before she had finished all growth in height and weight. Immobilization of the subcutaneous patch over time by the surrounding tissue, body movements and being situated in the costal margin could have placed additional stress on the lead and caused the fracture.

In our opinion the mechanism of subcutaneous patch lead fracture differs between pediatric and elderly patients and is not only dependent on a costal margin site; in children body growth is the main cause and in elderly patients it is rigidity of the patch. A possible way of preventing fracture of the subcutaneous lead is to decrease the stress on lead by making it more mobile and loose, although the growth of surrounding tissue into the patch soon makes the lead rigid and therefore more fragile.

Taking all this into account, we suggest that fracture of the subcutaneous patch lead in children is a more patientrelated than device-related complication. We also believe that the risk of fracture of the subcutaneous coil electrode connected to an abdominally implanted device is lower than for the subcutaneous patch electrode because the position of the subcutaneous lead creates a fibrous tunnel, which separates the lead from the surrounding tissue and allows the lead to follow the body movement. Body growth remains a definite problem, even with this sort of lead, and an endocardial system should be used in children whenever possible $!^{7}$

\section{Conclusion}

There is a new solution for patients with 'active can' ICDs who need a subcutaneous patch electrode for safe defibrillation: placement of a subcutaneous coil SQ electrode, instead of a patch, with satisfactory defibrillation threshold and very low risk of fracture.

\section{Acknowledgments}

The authors thank Dr Thomas Buckingham and Professor Yoshio Watanbe for their assistance with the manuscript.

\section{References}

1. Friedmand R, Grason A. Implantable defibrillators in children. I. Cardiovasc Electrophysiol 2001; 12: 361-362.

2. Brady PA, Friedman PA, Trusty JM, Grice S, Hammill SC, Stanton MS. High failure rate for an epicardial implantable cardioverterdefibrillator lead: Implications for long-term follow-up of patients with an implantable cardioverter-defibrillator. J Am Coll Cardiol 1998; 31: 616-622.

3. Gradaus R, Hammel D, Kotthoff S, Bocker D. Nonthoracotomy implantable cardioverter defibrillator placement in children: Use of subcutaneous array leads and abnormally placed implantable cardioverter defibrillators in children. $J$ Cardiovasc Electrophysiol 2001; 12: 356-360.

4. Stevens J, Buchwald AB, Krieglstein H, Unterberg C. Early detection of lead fracture by painless high voltage lead impedance measurement in a transvenous ICD lead system. J Interv Card Electrophysiol 2000; 4: 269-272.

5. Mera F, DeLurgio DB, Langberg JJ, Moss EA, Leon AR. Transvenous cardioverter defibrillator lead malfunction due to terminal connector damage in pectoral implants. Pacing Clin Electrophysiol 1999; 22: 1797-1801.

6. Kuisma M, Suminen P, Korpela R. Pediatric out of hospital cardiac arrest: Epidemiology and outcome. Resuscitation 1995; 30: $141-$ 150 .

7. Fischbach PS, Law ICH, Dick M II, Lerry S, Musca RS, Seruver GA. Use of a single coil transvenous electrode with an abdominally placed implantable-cardioverter defibrillators in children. Pacing Clin Electrophysiol 2000; 23: 884-887.

8. Gupta A, Zegel HG, Dravid VS, Nierenberg SJ, Freiman DB. Value of radiography in diagnosing complications of cardioverter defibrillators implanted without thoracotomy in 437 patients. Am J Roentgenol 1997; 168: 105-108.

9. Korte T, Jung W, Spehl S, Wolpert C, Moosdorf R, Manz M, et al. Incidence of ICD lead related complications during long-term follow-up: Comparison of epicardial and endocardial electrode systems. Pacing Clin Electrophysiol 1995; 18: 2053-2061.

10. Fahy GJ, Kleman JM, Wilkoff BL, Morant VA, Pinski SL. Low incidence of lead related complications associated with nonthoracotomy implantable cardioverter defibrillator systems. Pacing Clin Electrophysiol 1995; 18: $172-178$.

11. Mehdirad AA, Stohr EC, Love CJ, Nelson SD, Schaal SF. Implantable defibrillators impedance measurement using pacing pulses versus shock delivery with intact and modified high voltage lead system. Pacing Clin Electrophysiol 1999; 22: 437-441.

12. Schwartzman D, Nallamothu N, Callans DJ, Preminger MW, Gottlieb CD. Postoperative lead-related complications in patients with nonthoracotomy defibrillation lead systems. J Am Coll Cardiol 1995; 26: 776-786.

13. Hauser RG, Cannom D, Hayes DL, Parsonnet V, Hayes J, Ratliff N 3rd, et al. Long-term structural failure of coaxial polyurethane implantable cardioverter defibrillator leads. Pacing Clin Electrophysiol 2002; 25: 879-882.

14. Antonelli D, Rosenfeld T, Freedberg NA, Palma E, Gross JN, Furman S. Insulation lead failure: Is it a matter of insulation coating, venous approach, or both? Pacing Clin Electrophysiol 1998; 21: $418-421$.

15. de Voogt WG. Pacemaker leads: Performance and progress. Am J Cardiol 1999; 83: 187D-191D.

16. Frame R, Brodman R, Furman S, Gross J, Kim SG, Ferrick K, et al. Long-term stability of defibrillation thresholds with intrapericardiac defibrillator patches. Pacing Clin Electrophysiol 1993; 16: 208-212.

17. Wilson WR, Greer GE, Grubb BP. Implantable cardioverter-defibrillators in children: A single-institutional experience. Ann Thorac Surg 1998; 65: 775-778.

18. Oto A, Atalar E, Yildirir A, Kabakci G. Inappropriate shocks diagnosed by stored electrograms of implantable cardioverter defibrillators: Two case reports. Angiology 2000; 51: 425-430.

19. Geist M, Newman D, Greene M, Paquette M, Dorian P. Permanent explanation of implantable cardioverter defibrillators. Pacing Clin Electrophysiol 2000; 23: 2024-2029.

20. Korley VJ, Hallet N, Daoust M, Epstein LM. A novel indication for transvenous lead extraction: Upgrading implantable cardioverter defibrillator systems. J Interv Card Electrophysiol 2000; 4: $523-$ 528. 